2012

\title{
Marketing and Public Policy: Transformative Research in Developing Markets
}

Clifford J. Shultz

Loyola University Chicago, cshultz@luc.edu

Rohit Deshpande

Bettina Cornwell

Ahmet Ekici

\section{Recommended Citation}

Clifford J. Shultz, II, Rohit Deshpandé, T. Bettina Cornwell, Ahmet Ekici, Prabakar Kothandaraman, Mark Peterson, Stanley Shapiro, Debabrata Talukdar, Ann Veeck (2012) Marketing and Public Policy: Transformative Research in Developing Markets. Journal of Public Policy \& Marketing: Fall 2012, Vol. 31, No. 2, pp. 178-184. 


\title{
Marketing and Public Policy: Transformative Research in Developing Markets
}

\author{
Clifford J. Shultz II, Rohit Deshpandé, T. Bettina Cornwell, \\ Ahmet Ekici, Prabakar Kothandaraman, Mark Peterson, \\ Stanley Shapiro, Debabrata Talukdar, and Ann Veeck
}

\begin{abstract}
Developing markets are a challenge for researchers who study them and for governments, business leaders, and citizens who strive to improve the quality of life in them. The limitations of the dominant development paradigm coupled with the need to focus on consumers provide tremendous opportunities to engage in truly transformative research. Toward this outcome, several interactive forces must be understood and addressed during research design, management, and implementation. The purpose of this essay is to provide a synthesis — that is, a framework in the form of a conceptual model — with practical applications to transformative research in developing markets and, ultimately, with the broader objective to stimulate new conceptualizations, research, and best practices to transform consumer well-being.
\end{abstract}

Keywords: developing markets, economic development, consumer welfare, millennium goals

T he study of developing markets presents challenges and opportunities for researchers in marketing, policy, and consumer behavior. Yet, despite the generally agreed-on importance of developing markets, various research perspectives, methods, and measures often conflict, frequently produce mixed results, and may lead to dubious, if not deleterious, outcomes for some consumers

Clifford J. Shultz I/ is Professor and Charles H. Kellstadt Chair of Marketing, Quinlan School of Business, Loyola University Chicago (e-mail: cjs2@luc.edu). Rohit Deshpandé is Sebastian S. Kresge Professor of Marketing, Harvard Business School, Harvard University (email: rdeshpande@hbs.edu). T. Bettina Cornwell is Edwin E. and June Woldt Cone Professor of Marketing, Lundquist College of Business, University of Oregon (e-mail: Bettina.cornwell@gmail.com). Ahmet Ekici is an Assistant Professor, Faculty of Business Administration, Bilkent University (e-mail: ekici@bilkent.edu.tr). Prabakar Kothandaraman is Associate Professor of Professional Sales, Cotsakos College of Business, William Paterson University (e-mail: kothandaramanp@wpunj.edu). Mark Peterson is Associate Professor of Marketing, College of Business, University of Wyoming (e-mail: markpete@uwyo.edu). Stanley Shapiro is Professor Emeritus, School of Business, Simon Fraser University (e-mail: sshapiro@sfu.ca). Debabrata Talukdar is Professor of Marketing, School of Management, University at Buffalo, State University of New York (e-mail: dtalukda@buffalo.edu). Ann Veeck is Professor of Marketing, Haworth College of Business, Western Michigan University (e-mail: ann.veeck@ wmich.edu). The authors thank Ron Hill, Julie Ozanne, and Madhu Viswanathan for inviting their leadership of the Marketing and Development Track for the Second Conference on Transformative Consumer Research. They also thank the anonymous reviewers for many helpful comments. The authors are listed alphabetically after the second author. Stacey Baker served as associate editor for this article. (e.g., Moyo 2009). This reality, though perhaps perceived by some observers as counterintuitive or even contradictory, may be explained by the wide array of scholars studying "development" and the consequent conceptualizations and measurements of it.

The scholarly field of developing markets has largely been the domain of economists and financial analysts. The foci, nomenclature, constructs, research methods, measures, institutions, and resources therefore are often foreign to many marketing, public policy, and consumer behavior researchers, which can make the design and administration of transformative research somewhat daunting. Not that economists (e.g., Secondi 2008), marketing academics (e.g., Klein and Nason 2001), and consumer researchers (e.g., Belk 1988; Hill, Felice, and Ainscough 2007) have failed to make important contributions to understanding developing markets; rather, they have made important contributions, but long-standing trajectories and academic silos are problematic, prevent cooperation and fresh perspectives to chronic challenges, and tend to impede policies and practices that potentially could elicit the most desirable outcomes for the largest number of consumers over time.

The bottom-of-the-pyramid perspective has opened the eyes of many scholars and practitioners to the rewards and necessity of understanding developing markets (Prahalad 2005). Prahalad's (2005) efforts represent some of the most compelling transformative research to date, in many respects because the exemplary stories about producers and consumers are actually from citizens of developing countries. This highly visible work is reflective of growing interest in research communities to positively affect the stakeholders of marketing and consumption. Mick (2010), for example, encourages consumer behavior researchers to engage in "transformative consumer 
research ... a movement that seeks to encourage, support, and publicize research that benefits consumer welfare and quality of life for all beings affected by consumption across the world." This deliberately prosocial, catalytic approach to research coincides in many ways with positions espoused by complementary groups conducting research in marketing, policy, and macromarketing (see, e.g., Fisk 1981).

Such efforts indicate renewed and redoubled interest in developing markets among various scholarly communities and the interactive roles of marketing and policy in them. This interest has inspired eclectic conferences and new collaborations. The purpose of this essay is to synthesize ideas and interpretations that emerged during the Developing Markets track of the Second Transformative Consumer Research Conference in 2009, with hopes of stimulating public policy research in developing markets.

\section{Understanding Developing Markets}

What constitutes a developing market? From the work of Schumpeter (1911) to that of Sen (1999), many different constructs and measures have been studied. ${ }^{1}$ Broadly conceptualized, developing markets aspire to economic growth and/or improved welfare for people (Dapice 2008). More specific assessments have employed a battery of perspectives and measures. For example, the World Bank (2010a), a principal organizing body vis-à-vis conceptualization, measurement, policy, and practice, classifies economies by gross national income (GNI) per capita. To date, 210 countries have been categorized as low, middle, or high income. Low-income (GNI/capita of $\$ 975$ or less) and middleincome (GNI/capita from $\$ 976$ to $\$ 11,905)$ economies are sometimes referred to as "developing economies."2 Moreover, although countries and regions tend to be the units of analysis, any aggregation of consumers - provinces, counties, cities, tribes, communities - could be considered and studied as developing markets; in turn, policy change and marketing endeavors could target larger or smaller aggregations (Annan 2000).

Developing markets have been studied principally through the lenses of economics, geography, marketing, political science, and finance, which have tended to measure economic, financial, market, and political trends rather than consumer security, wellness, or happiness. Developing markets are more than geopolitical entities; thus, they should be assessed more holistically (e.g., Klein and Nason 2001) and systemically (e.g., Layton 2009). The Human Development Index (HDI) is one measure that moves toward this objective-making human beings and their wellness the focal point of development and, in turn, helping people actualize

\footnotetext{
1Our charge was not to provide a review of the voluminous literature on marketing and development, emerging markets and development, subsistence markets, developing economies, or similar constructs, which often overlap and transcend the boundaries of academic disciplines. We do briefly introduce the evolving and sometimes complex and expansive conceptualizations and measures of development, which in turn provide research opportunities for marketing, consumer research, and policy scholars.

2These dollar parameters are based on 2008 data, the most recently reported. Geographic regions are also used for analytical purposes. Note that though countries may have similar GNI/capita, they may experience dissimilar development.
}

their potential, increase their choices, and enjoy freedom to lead valued lives (United Nations Development Programme 2010). The most recent iteration of the Human Development Report ranks 182 countries on the basis of their HDI scores (United Nations Development Programme 2009). Of these, 83 countries are listed as high to very high on human development, and 99 are listed as medium to low. ${ }^{3}$ A more comprehensive battery can be found in the form of World Development Indicators (WDI). The WDI includes more than 1000 measures that researchers can use to examine "development" from myriad perspectives through numerous indexes (World Bank 2011).

Although these examples hint at a growing appreciation of the complexity of development, a thoughtful review of the literature and the fieldwork of the authors of this article suggest that if marketing and policy are to transform the well-being of people in developing markets, many forces and factors must be addressed, including the facilitative conceptualization of people as consumers - who are integral to a marketing system - and the contexts of that system that affect their outcomes. Ger (1997, p. 116), for example, provides a thoughtful review on marketing and policy in developing countries and, in particular, on the "social links and power relations" that need to be understood. A focus on relationships among groups of consumers and comparison with real or imagined reference groups in a country or abroad shows that a straightforward analysis of quantitative differences in the HDI, WDI, and perhaps any index does not fully reveal inequalities and lifestyle polarities. Again, the development process is complex and systemic; therefore, meaningful study must address this underlying complexity and the forces that abet consumer well-being. We now address this idea in more detail.

\section{Toward a Framework for Transformative Research in Developing Markets}

We take a systemic approach to establish our framework, which includes the goal of consumer well-being. Ultimately, our primary interest is social welfare; the phenomena, forces, factors, and policies that affect welfare, and the methods employed to study them, should be change agents for consumer transformation. Such consequence-based thinking is grounded in the moral philosophy of utilitarianism originating in the work of the nineteenth-century English philosophers and social reformers Jeremy Bentham (1890) and John Stuart Mill (1871). Practically, we are interested in discovering drivers of best practices, as they affect (and are affected by) the marketing system; we concomitantly are interested in discovering the extent to which practices are indeed "best." 4 Any such discovery is determined by the extent to which the well-being of consumers in that system is enhanced.

In the framework of Figure 1, our intent is twofold: to prove that consumer well-being needs a holistic and systemic perspective and to show that well-being is dynamic,

\footnotetext{
${ }^{3}$ Similar to many measures or indexes, HDI is not without its critics (see, e.g., Hastings 2009)

4To reinforce this point, we emphasize that "best" is a relative term and may be specific to time, place, person, community, region, and/or country.
} 


\section{Figure 1. Toward a Framework for Transformative Research in Developing Markets}

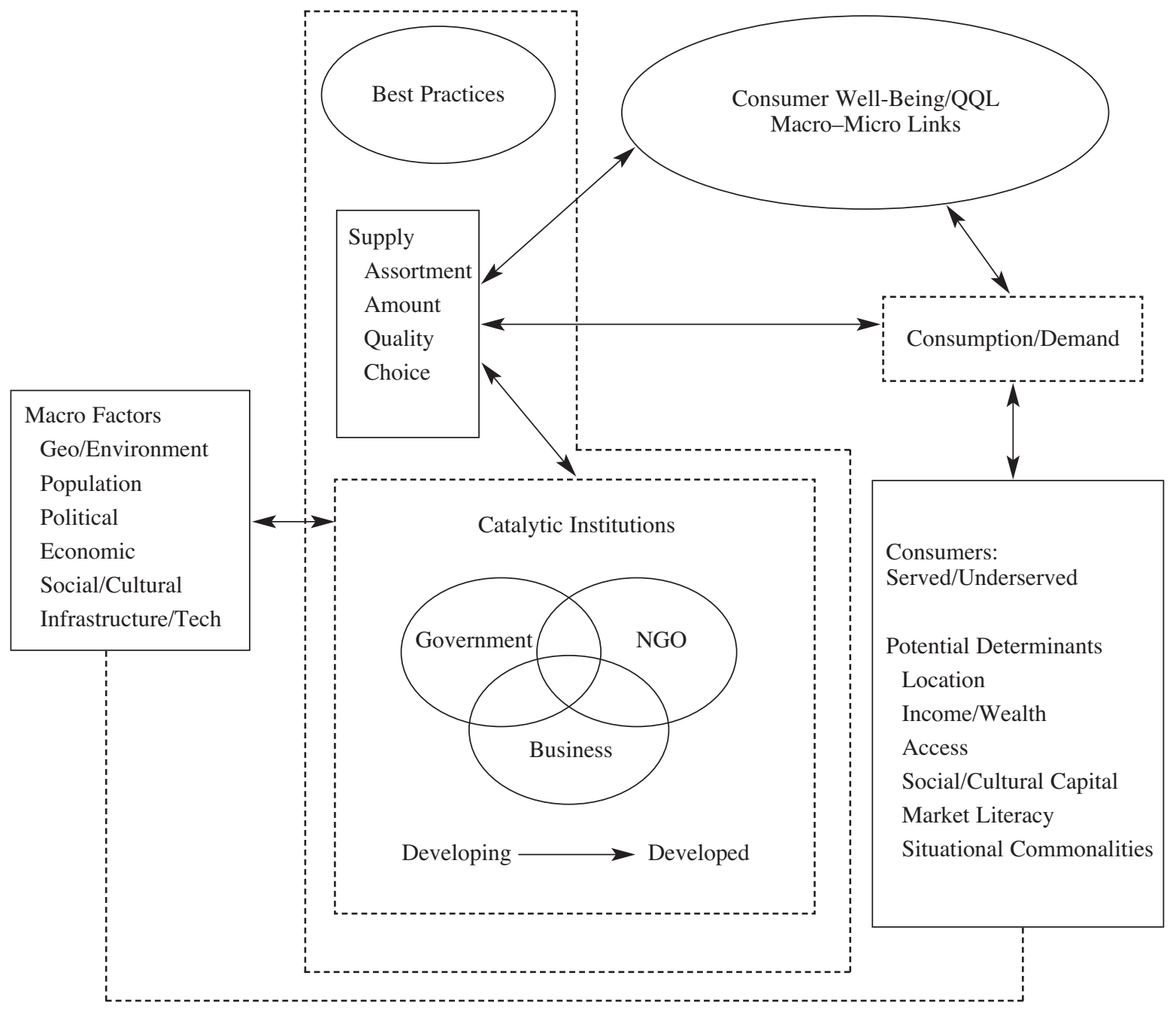

with greater consumer well-being reinforcing the specific drivers that enhance it. This second point suggests feedback and is shown by double-headed arrows. The intent of this framework is to demonstrate that long-term, sustainable consumer well-being transfers agency to local underserved consumers themselves in a Gandhian sense of "selfreliance" and as increasingly championed by some development scholars (e.g., Chambers 1997). What follows is a brief articulation of each model component.

\section{Macro Factors}

Decisions, policies, and practices are greatly affected by macro forces. These forces appear on the left-hand side of Figure 1 and show temporal order. More specifically, the nature of any place-its geography and environmental condition-determines who is there, what resources can be leveraged to build society, what cultures and administrative organizations have emerged, what colonizing powers (if any) were attracted to them, and, almost inevitably, the con- dition of any extant marketing system (e.g., Shultz and Pecotich 1997). For example, the natural conditions and peoples in arid Namibia are markedly different from those in Java. The European colonizers of each-Germany and the Netherlands, respectively_brought different ideas, administrative practices, and technologies, the remnants of which affect current and future consumption environments and, implicitly, any future transformation. The current governments, businesses, and nongovernmental organizations (NGOs) also function dissimilarly, largely because of the variances in natural, cultural, technological, and administrative legacies. 5

These macro forces can and often do have a direct impact on marketing institutions and consumers (see the

${ }^{5}$ Before the arrival of the Dutch, Java was a center of Hindu/Buddhist empires and then Islamic Sultanates. Thus, Java, now part of Indonesia, is a crucible of traditions, practices, and institutions affecting consumption and Indonesia's development. 
dotted line in Figure 1 connecting them to consumers). However, the extent to which they are mitigated or managed, or the extent to which changes are deliberately made to the aggregated marketing system, is greatly determined by governments, businesses, and NGOs. This governmentbusiness-NGO triad can be either pernicious and predatory or benevolent and beneficial. An illustrative comparative example is the management of the earthquakes in Chile (February 27, 2010) and Haiti (January 12, 2010); the former constitutes a best practice exemplifying many aspects of the framework, in contrast with the postcrisis conditions in Haiti (David Rockefeller Center for Latin American Studies 2010). The benevolent outcomes are more likely when systemwide best practices are sought and implemented, an idea to which we turn next.

\section{Best Practices: Governments, Businesses, NGOs}

Best practices appear at the top of Figure 1, a symbolic positioning indicating that much of the well-being of consumers in developing markets is a function of policy and practices established by key catalytic institutions: governments, businesses, and NGOs. Note that the boundary of this construct (catalytic institutions) is permeable, to emphasize that best (and worst) practices have an impact on all aspects of the system. Note also that the three catalysts are found in both developing and developed markets. The U.S. government and many U.S. businesses, for example, may work with the government of a developing market or several markets through the United States Agency for International Development, an NGO, or foreign direct investment, with the objective to facilitate development. Specific successful programs include environmental sustainability, micro loans and business start-ups, cell phone "banks," literacy, potable water, immunization, sports/arts, and marketbased literacy.

The construct also indicates a hopeful development continuum, in which formerly developing economies (e.g., Singapore) evolve to a point where they have the economic foundation to participate as development donors. Further to the developed or donor end of this continuum, developed markets could engage best practices to assist developing markets by revisiting farm subsidies and trade agreements, eliminating consumption of illicit products/narcotics (coupled with crop substitution assistance), and curtailing human trafficking. Developed markets may engage in fair trade, voluntary simplicity, consumption with the purpose to support poor economies (ecotourism, trade preference), and reduced consumption of some products. In developing markets, we must ask the following: Do the efforts of catalytic institutions supply goods and services that consumers value? Is there adequate assortment, are the amounts appropriate, and are the goods/services of sufficient quality and price to provide basic sustenance or perhaps even joy? Are there choices regarding what, when, where, how, how much, and with whom to consume? Do consumers choose "wisely," are they being lifted from poverty, are they empowered? Are they safe, happy, and healthy? Is family and community welfare improving? Affirmative answers to these questions would seem to connote positive catalytic effect by these institutions, further indicating that their efforts could be categorized as best practices.

\section{Served/Underserved Consumers}

Almost by definition, developing markets have a disproportionately large number of consumers who are underserved, even when best practices reach others (e.g., oligarchs, elites) who are served well or adequately. Several potential factors influence whether consumer groups in developing markets are served, including location, income/wealth, access, market literacy, political will, and situational commonalities. Location, or the proximity to resources, is especially important. If a person is geographically disadvantaged by being physically distant from resources, he or she is likely to be underserved. Thus, even a basic medical outpost may not serve the unwell if they cannot afford the basic transportation for even short distances. The problems of spatial disparity and dense overcrowding are exacerbated in poorer countries, which may not have assets to mobilize development programs. Low income or the absence of wealth more generally, whether at the national or individual level, similarly confounds efforts to serve disadvantaged groups, as do the previously mentioned relative social standings and inequalities.

In addition to having limited access physically, underserved consumer groups also may lack social or cultural capital, which further hinders access. Social class, education, ethnicity, religion, political affinity, and networks and relationships (and possible ostracism from both) could all limit social or cultural capital, which in turn could limit the availability of resources to stimulate development. In worst cases, absence of social/cultural capital not only impedes development but also can result in ethnic cleansing or even genocide, as has occurred in Cambodia, regions of the Balkans, and, most recently, Darfur. Thus, political willinspired by a vision of the greater good-in addition to financial capital, is required for effective development.

Even when physical, financial, and cultural barriers are relatively low, market literacy remains a challenge. People targeted for development assistance or investment must have the necessary understanding and skills to participate in and make contributions to marketing endeavors that will produce desirable socioeconomic indicators.

\section{Consumer Well-Being, Quality of Life, and Macro-Micro Links}

The measure of whether markets truly are developing, or whether the marketing system is administered effectively and justly, is the extent to which human well-being is improving on subjective and objective measures. Our review of best practices suggests that such administrative leadership can emanate from different actors, governments, NGOs, and consumer activist groups, as long as they are focused on ultimate transformative well-being and take the kind of holistic and systemic approach we describe in Figure 1.

Although many institutions favor aggregated economic performance measures, often at the expense of considerations of wellness, happiness, and quality of life, some hope for a new order has emerged from the HDI, WDI, and Human Development Reports. More recently, the Millennium Development Goals, also initiated by the United Nations Development Programme (2010b), show promise because they are transformative consumer metrics, not only in their foci but 
also by apparent acceptance among catalysts and consumer groups. Briefly, these goals include eradicating extreme poverty and hunger; achieving universal primary education; promoting gender equality and empowering women; reducing child mortality; improving maternal health; combating HIV/AIDS, malaria, and other diseases; ensuring environmental sustainability; and developing a global partnership for development (see also World Bank 2010b).

Progress toward these goals is focused on quantifiable targets measured by 60 indicators. In reviewing these goals, targets, and indicators, we find opportunities for greater orientation toward consumers. For example, although an implicit wellness-focused bill of human rights is emerging, we also believe the goals would be strengthened by inclusion of consumer rights (see United Nations 1948). Furthermore, a consumer- and/or consumption-focused connection between markets and people would present numerous opportunities for multimethod research, with the potential to be transformative for consumers. In this regard, the emerging work on consumer quality of life would seem especially timely and useful (e.g., Ekici and Peterson 2009; Sirgy et al. 2008), as is research by the University of Bath group (Gough and McGregor 2007) and more recent explorations of consumer well-being in subsistence markets (e.g., Ozanne and Saatcioglu 2007; Rosa and Geiger-Oneto 2009; Viswanathan, Rosa, and Ruth 2010).

Further United Nations recommendations for "global partnership for development" note that the program is explicitly systemic, requiring macro-micro linkages, global coordination, and compromise; partnerships can only be achieved "if all actors work together and do their part. Poor countries have pledged to govern better, and invest in their people through health care and education. Rich countries have pledged to support them, through aid, debt relief, and fairer trade" (United Nations 2007). Without a wellconceived, well-orchestrated, inclusive, and benevolent effort linking governments, businesses, multilateral organizations, communities, and consumers, development is unlikely to occur. Large-scale transformation - that is, a national or regional shift from consumer suffering to consumer wellbeing-also is unlikely. This would seem especially true when taking on the most insidious of well-being challenges that impede development, including globalization and consumer participation/disenfranchisement (e.g., Cornwell and Drennan 2004), control or elimination of the spread of infectious diseases (e.g., Chance and Deshpandé 2009), and the stopping or prevention of wars (Shultz et al. 2005).

\section{Research in the Future}

The framework we develop herein is in line with work published in, for example, Bloom and Gundlach (2001). Their conceptual model, "The Paths Through Which Marketing Affects Societal Welfare," commonly reflects the current model's end goal of positive societal outcomes. Their work differs from the current thinking in that it is oriented toward marketing knowledge and its use in decision making, whereas the current work aims to build a framework for conducting research. The rudimentary sketch of transformative research in developing markets (see Figure 1) suggests several unique starting points for a research agenda, including process and content.

\section{Research Process}

\section{Relationships: Conceptual, Empirical, and Personal}

We present a conceptual framework for transformative consumer research. We envision numerous studies that could assess or measure relationships among the factors in Figure 1. For example, which factors have the greatest effect on consumer well-being in specific developing market contexts? Do our assertions regarding the model withstand further empirical scrutiny, using eclectic methods? Given new findings, how can the framework be expanded? Developing markets are not merely places where poor consumers live. They often are places with large income and lifestyle inequalities and polarities. How do these inequalities and polarities affect development, consumer transformation, and well-being? What relationships among groups of consumers and comparisons with real or imagined reference groups within the country/region or abroad are critical to effect transformation? How might the diaspora, for example, be helpful, as witnessed in China, Israel, and the Balkans but less apparent in Cambodia?

\section{Silo-Bridging Work}

Although important efforts in a positive direction, such as the Millennium Development Goals, outline targets, for many catalytic institutions, transformative consumer research seems distant from these goals and potentially opportunistic. On closer examination, these goals are naturally ensconced in consumer behavior. For example, a compendium of consumer behaviors as varied as food choice, transportation decisions, and condom use influences health quality. When aspects of overarching challenges are examined as changes to simple repeated consumer behaviors, the role for marketing and consumer researchers is made clear. Initial research could break down large goals to find key consumer behaviors. Also needed is a common nomenclature that can be the basis for true cross-disciplinary, crossinstitutional research.

\section{Transformative Teams}

Developing markets often have entrenched, systemic issues that are resistant to piecemeal interventions. If transformative consumer research is to be more than a discussion, it will require teams of researchers coming together to focus on a problem. They must focus on issues that constitute priorities for the most disenfranchised people, that are doable within the boundaries of institutions, and that can be leveraged by application in other contexts. A starting point would be development of a shared conversation space in which constituents come together to discuss priorities, vet research ideas, and find research partners.

\section{Making Space}

Transformative research in developing markets must first appear on the individual researcher's agenda. The researcher should begin by allocating part of his or her stream of research to transformative topics. Doing so may require broad-minded thinking to extend current research interests to developing markets and transformative agendas. Commitment to this type of research may also require 
explaining transformative research to review panels, university administrators, and peers.

\section{Assumption Breaking Agendas}

\section{Building on the Past}

Although new thinking needs to be applied in developing markets, already-identified research agendas needing action exist. For example, Witkowski's (2005) primer on the challenges facing marketers in developing countries opens a discussion on antiglobal issues (e.g., the potential for marketing to undermine local culture) deserving researcher and policy attention. Ger (1999) examines ways to support local firms working within global contexts, but more work is needed. Another example in which marketing and policy come together is NGOs; Talukdar, Gulyani, and Salmen (2005) offer insights on marketing in World Bank projects. Yet another starting point that builds on already-developed knowledge is the recently summarized macromarketing collection (Shapiro, Tadajewski, and Shultz 2009) in which thinking on marketing systems, societal development, equity, and poverty is organized for readers.

\section{Articulating the Value of Marketing in Policy}

Marketing has played a niche role in training for cottage industries, an example of which is the success of Global Mamas, a nonprofit and fair-trade organization assisting women in Africa. The potential contribution of combined marketing and policy research in transforming developing markets has, however, not even reached the agenda of many. Exceptions exist; for example, the Bill and Melinda Gates Foundation (http://www.gatesfoundation.org) focuses largely on infectious diseases, and its delivery platform addresses obstacles that typically prevent adoption and uptake. In the fight against malaria, the decision to buy or receive donated mosquito netting is a basic example of consumer behavior.

\section{Learning from Past Trajectories}

How transferable is knowledge across developed and developing markets? Many of the challenges facing developing markets have been explored, but the learning needs to be complied to be informative. Consider, for example, the recent oil discoveries in offshore Jubilee Field of Ghana. What can be learned from the United Arab Emirates and its limit of state control of oil companies or from Alaska and its redistribution of oil income through the Alaska Permanent Fund? What model would result in the most humanitarian improvement to well-being in Ghana? How can marketing and public policy work together for the greater good?

\section{Expediting the Marketing-Policy Discourse}

What policies do developed markets enjoy that developing markets do not? The World Health Organization (2009) details the share of world population covered by various tobacco control policies - for example, $8 \%$ of the world's population benefit from health warnings on packaging, but only $5 \%$ benefit from smoke-free environments. Moreover, taxes on tobacco are typically not employed in tobacco control. What is the role of marketing and public policy in communication and control?

\section{Conclusion}

Our synthesis and subsequent framework include numerous opportunities for research and collaboration to effect transformative well-being. We assert that transformation for developing markets and economies is supported when marketing is coupled with policy - that is, the cooperation of both in an indispensable interplay driven by broad societal outcomes in the form of enhanced consumer well-being, as determined by multiple measures and holistic interpretations. Such interplay is most likely to be supported in societies if the focus and design of research coincide with the interests of both catalytic institutions and consumers. Many research tools from various disciplines can assist in gaining understanding and, subsequently, in affecting policy. However, initiatives may require understanding of conventional/traditional foci and methods and perhaps related positioning and articulation. Such bridge building may be imperative to make the case to traditionally (i.e., nonmarketing) trained gatekeepers and policy makers that missed opportunities exist in consumer behavior and that transformative research ultimately is vital to development programs.

\section{References}

Annan, Kofi (2000), "Address to the Tenth United Nations Conference on Trade and Development," United Nations Information Services, Bangkok, Thailand (February 12), (accessed June 10, 2011), [available at http://www.unescap.org/unis/press/ G_05_00.htm].

Belk, Russell W. (1988), "Third World Consumer Culture," in Marketing and Development: Toward Broader Dimensions, E. Kumcu and A.F. Firat, eds. Greenwich, CT: JAI Press, 113-28.

Bentham, Jeremy (1890), Utilitarianism. London: Progressive Publishing Company.

Bloom, Paul N. and Gregory T. Gundlach (2001), Handbook of Marketing and Society. Thousand Oaks, CA: Sage Publications.

Chambers, Robert (1997), Whose Reality Counts? Putting the First Last. London: Intermediate Technology Publications.

Chance, Zoë and Rohit Deshpandé (2009), "Putting Patients First: Social Marketing Strategies for Treating HIV in Developing Nations," Journal of Macromarketing, 29 (3), 220-32.

Cornwell, T. Bettina and Judy Drennan (2004), "Cross-Cultural Consumer/Consumption Research: Dealing with Issues Emerging from Globalization and Fragmentation," Journal of Macromarketing, 24 (2), 108-121.

Dapice, David (2008), "What Do We Know About Economic Development?” Journal of Macromarketing, 28 (4), 413-17.

David Rockefeller Center for Latin American Studies (2010), "Reacting and Acting: Lessons from Haiti and Chile," panel session, Harvard University (May 15).

Ekici, Ahmet and Mark Peterson (2009), "The Unique Relationship Between Quality of Life and Consumer Trust in MarketRelated Institutions Among Financially Constrained Consumers in a Developing Country," Journal of Public Policy \& Marketing , 28 (Spring), 56-70.

Fisk, George (1981), "An Invitation to Participate in Affairs of the Journal of Macromarketing," Journal of Macromarketing, 1 (1), 3-6. 
Ger, Güliz (1997), "Human Development and Humane Consumption: Well-Being Beyond the Good Life," Journal of Public Policy \& Marketing, 16 (Spring), 110-25.

_ (1999), "Localizing in the Global Village: Local Firms Competing in Global Markets," California Management Review, 41 (4), 64-83.

Gough, Ian and J. Allister McGregor (2007), Well-Being in Developing Countries: From Theory to Research. Cambridge, MA: Cambridge University Press.

Hastings, David A. (2009), "Filling Gaps in the Human Development Index: Findings for Asia and the Pacific," working paper, Information and Communication Technology and Disaster Risk Reduction Division, United Nations ESCAP.

Hill, Ronald Paul, William F. Felice, and Thomas Ainscough (2007), "International Human Rights and Consumer Quality of Life: An Ethical Perspective," Journal of Macromarketing, 27 (4), 370-79.

Klein, Thomas A. and Robert W. Nason (2001), "Marketing and Development: Macromarketing Perspectives," in Handbook of Marketing and Society, Paul Bloom and Gregory Gundlach, eds. Thousand Oaks, CA: Sage Publications, 263-97.

Layton, Roger A. (2009), "On Economic Growth, Marketing Systems, and the Quality of Life," Journal of Macromarketing, 29 (4), 349-62.

Mick, David Glen (2010), “Transformative Consumer Research," (accessed February 1, 2010), [available at www.acrwebsite.org/ fop/index .asp?itemID=325].

Mill, John Stuart (1871), Utilitarianism. London: Longmans, Green, Reader, and Dyer.

Moyo, Dambisa (2009), Dead Aid: Why Aid Is Not Working and How There Is Another Way for Africa. London: Allen Lane.

Ozanne, Julie L. and Bige Saatcioglu (2007), "Understanding Subsistence Marketplaces: Exploring the Contributions of Participatory Action Research," in Advances in International Management: Product and Market Development for Subsistence Marketplaces, Vol. 20, J. Rosa and M. Viswanathan, eds. London: Elsevier, 111-32.

Prahalad, C.K. (2005), The Fortune at the Bottom of the Pyramid: Eradicating Poverty Through Profits. Upper Saddle River, NJ: Wharton School Publishing.

Rosa, José Antonio and Stephanie Geiger-Oneto (2009), "Social Strain as an Antecedent of Innovativeness Among Subsistence Consumers," in Advances in Consumer Research, Vol. 36, Ann L. McGill and Sharon Shavitt, eds. Duluth, MN: Association for Consumer Research, 114-18.

Schumpeter, Joseph Alois (1911), Theorie der Wirtschaftlichen Entwicklung (The Theory of Economic Development). Berlin: Duncker \& Humblot.

Secondi, Giorgio (2008), The Development Economics Reader. New York: Routledge.

Sen, Amartya Kumar (1999), Development as Freedom. New York: Knopf.

Shapiro, Stanley J., Mark Tadajewski, and Clifford J. Shultz (2009), "Interpreting Macromarketing: The Construction of a
Major Macromarketing Research Collection," Journal of Macromarketing, 29 (3), 325-34.

Shultz, Clifford J., Timothy J. Burkink, Bruno Grbac, and Nataša Renko (2005), "When Policies and Marketing Systems Explode: An Assessment of Food Marketing in the WarRavaged Balkans and Implications for Recovery, Sustainable Peace, and Prosperity," Journal of Public Policy \& Marketing, 24 (Spring), 24-37.

Shultz, Clifford J. and Anthony Pecotich (1997), "Marketing and Development in the Transition Economies of Southeast Asia: Policy Explication, Assessment, and Implications," Journal of Public Policy \& Marketing, 16 (Spring), 55-68.

Sirgy, J. D.-J. Lee, S. Grzeskowiak, J.-C. Chebat, J.S. Johar, A. Hermann, S.H.I. Hegazi, et al. (2008), "An Extension and Further Validation of a Community-Based Consumer Well-Being Measure," Journal of Macromarketing, 28 (3), 243-57.

Talukdar, Debabrata, Sumila Gulyani, and Lawrence F. Salmen (2005), "Customer Orientation in the Context of Development Projects: Insights from the World Bank," Journal of Public Policy \& Marketing, 24 (Spring), 100-111.

United Nations (1948), "The Universal Declaration of Human Rights," (accessed July 22, 2010), [available at http://www. un.org/en/documents/udhr/].

- (2007), "About the Millennium Development Goals," (accessed February 2, 2012), [available at http://www.un. cv/mdgs.php].

United Nations Development Programme (2009), Human Development Report. New York: United Nations.

(2010), "The Millennium Development Goals: Eight Goals for 2015," (accessed February 2, 2010), [available at http:// www.undp.org/mdg/]

Viswanathan, Madhu, José Antonio Rosa, and Julie A. Ruth (2010), "Exchanges in Marketing Systems: The Case of Subsistence Consumer-Merchants in Chennai, India," Journal of Marketing, 74 (May), 1-17.

Witkowski, Terrence H. (2005), “Antiglobal Challenges to Marketing in Developing Countries: Exploring the Ideological Divide," Journal of Public Policy \& Marketing, 24 (Spring), 7-23.

The World Bank (2010a), "How We Classify Countries, (accessed March 23, 2010), [available at http://web.worldbank.org/ WBSITE/EXTERNAL/DATASTATISTICS/0,,contentMDK: 20420458 menuPK:64133156 pagePK:64133150 piPK: 64133175 theSitePK:239419,00.html].

_ (2010b), "The Millennium Development Goals Are a Challenge the Global Community Has Set for Itself," (accessed March 23, 2010), [available at http://devdata.worldbank. org/atlas-mdg/].

(2011), "World Development Indicators," (accessed June 10, 2011), [available at http://data.worldbank.org/data-catalog/ world-development-indicators].

World Health Organization (2009), WHO Report on the Global Tobacco Epidemic, 2009. Geneva, Switzerland: WHO Press. 
Copyright of Journal of Public Policy \& Marketing is the property of American Marketing Association and its content may not be copied or emailed to multiple sites or posted to a listserv without the copyright holder's express written permission. However, users may print, download, or email articles for individual use. 